\title{
Adversities Livelihood and Copping Strategies of Slum Area Residents in Gondar City: North West Ethiopia
}

\author{
Alemayehu Mulat Liyew \\ Lecturer, Department of Sociology, Debre Markos University, Debre Markos, Ethiopia
}

\begin{abstract}
Slum development has been negative result of urbanization in developing country like Ethiopia. One of the metropolitan cities in Ethiopia, Gondar faced this problem. Hence, this study aimed at investigating the physical environment, means of livelihood, health situation and social network of residents in Gojjo sefer slum area in Gondar city. Qualitative research design, phenomenological approach was employed to understand the real life experience of slum dweller in the study area. 35 participants were sampled purposively among 83 total habitants. Accordingly, data was collected by in-depth interview, key informant interview and field observation. The findings show that, congested and poorly constructed housing, inadequate infrastructure and social service provision characterize the area. Most of the dwellers are immigrants from rural area engaged in petty economic activities as a means of livelihood. The dwellers have being suffered from varieties of problems such as low income, lack of health care services and are exposed to frequent disease such as diarrhea, fever and chronic illnesses.
\end{abstract}

Keywords: slum, livelihood, adversities, dwellers

DOI: $10.7176 / \mathrm{CER} / 12-9-02$

Publication date:September $30^{\text {th }} 2020$

\section{Introduction}

Rapid urbanization comes with myriads of problems such as of squatter settlement and slum development in developing countries (World bank, 1993).The current existence and continued formation as well as expansion of slums at unprecedented rate are one of the challenges encountering cities in Sub-Saharan African (SSA) countries. Numbers of slum dwellers in developing countries had increased from 657 million (1990) to 767million (2000), and are estimated to be 828 million in 2011(World Bank, 2011). Although international, national, and local initiatives have made significant efforts to tackle the problem of the growth of slums, unfortunately, the rapid growth of urbanization and the actual trend of population growth in SSA have eclipsed their efforts(Berger, 2006).

Slum areas characterized by high rates of poverty, illiteracy and bad health status. Dwellers have low earning; they mostly do not have any formal education facilities, work in environment which is harmful to them. This fact forces them to work in informal sector (Alamgir, Jabbar et al. 2009). The situation of Ethiopia is not different from the rest of the world. The report of UN-HABITAT 2003 ,in Africa, shows that there are cities which have large number of people living in slum area, for Africa Addis Ababa ( the capital of Ethiopia), case, Kinshasa and Nairobi are the major ones. In Ethiopia slum area are expanding in many cities especially in the capital and big regional cites.

Gondar is one these relatively big regional cities which is found northern part of Ethiopia, at Amhara regional state, and it is $727 \mathrm{~km}$ far away from the capital city, Addis Ababa. Gondar is also a town in Ethiopia in which people are living with poor housing and low sanitary area. According to city administration report, 2009 in Gondar city administration more than 10 kebles (blocks, Now a days Gondar City is divided it to sub-cities (12 kifle ketemas) are affected significantly by different challenge from those who are affected by harmful pollutant and swages runs in open drains along the roads which providing a serious way for infectious disease. Because food, housing and drinking water are frequently contaminated, diarrhea is common especially among children and old persons (city Administration report, 2009, cited in Nayak 2013).

Even though researches have been conducted in the city, they focused on a single aspect or problem of urbanism like streetism (homelessness), crime, delinquency, unemployment, poverty, etc. As to the review of the researcher, they failed to consider the physical environment and livelihood of people in slums simultaneously.

Cognizant of this the study assessed the physical environmental, and livelihood strategies and health statuses of slum areas in Gondar city with a special reference to Arada Sub city slum area Gojjo Sefer. Moreover this study differ from others for it employed mainly quantitative research design and phenomenological approaches which enables to investigate the real lived experience of slum dwellers. Accordingly, the study objectives are; to describe the physical environment of the study area, called Gojjo Sefer in Gondar City; to assess the means of livelihood of the residents; to examine the health situation and finally the social network of residents in Gojjo sefer slum area.

\section{Research Method and Data Sources \\ Research Design}

In this research, qualitative research design was employed whereby households and key informants were selected 
purposely and are interviewed. In terms of time, a cross-sectional study design was employed to collect data and analyze at a point in time.

\section{Research approach; Phenomenology}

The concept phenomenology incorporates both philosophical ideology and numbers of research methods. When defined phenomenological research method (Creswell 2007pg 57 cited in Hermela 2018) “.... phenomenological study describes the meaning for several individuals of their lived experiences. Accordingly, this study investigated the lived experiences of slum-Gojjo Sefer dwellers to make sense from the respondents own perspective.

\section{The study Area}

The study is conducted at Gondar City, strategically located in the northern part of Ethiopia, in Amhara National Regional State, $727 \mathrm{~km}$, North from Addis Ababa and $150 \mathrm{~km}$ from Bahir Dar the regional capital. It is also32 km north of Lake Tana, and nestles in the foothills of the Semien mountains at 2,200 meters above sea level and also it covers an area of 257 Sq.km. Gondar has some of Ethiopia's most important historical sites. The city is one of the oldest and largest cities in Ethiopia. However, the city cannot achieve its good standard due to certain problems among one of which is of slums in the city mainly, Arada sub city. Hence the geographical scope of the study was Arada sub city (Kifle Ketema) slum area called Gojjo sefer. Because this area is the place where there is extreme poverty and overcrowded, deteriorated housings.

\section{Study population and sampling}

The main target populations of the study are people who are living in slum area of Arada sub city, Gojjo Sefer, Kebele 9 in Gondar City. In includes both man and women dweller settled in the area. 35 respondents from the 83 residents were sampled using purposive sampling techniques.

\section{Data Sources}

For the successful accomplishment of the study, both primary and secondary data have been used. While primary data was gathered from selected participants and different concerned bodies and secondary data was collected from both published and unpublished written materials which have great relevance for the study.

\section{Method of data collection}

In this study, the researcher employed in-depth interview, key informant interview (unstructured interview), and observation checklists to collect the qualitative data. In-depth interview was held with selected households of the slum area to get detailed data on the livelihood and health status and social network dwellers to understand their lived experiences. In addition, the Sub City official and project manager of Yenege Tesfa Orfan and Street Children Organization (NGO) were interviewed to get insight about their role in the process of solving the problem of the dwellers in the slum area. Besides, the researcher undertook observation on physical, social and living arrangements of the study area to supplement the above methods.

\section{Method of data analysis and Interpretation}

To facilitate the analysis, the collected data first translated and transcribed in to English. Then, the data was coded thematically, and analyzed and interpreted with respect to the actual situation and the available literatures.

\section{Findings}

\section{The physical and environmental condition of the area}

The area under study is located at Arada Sub City /Kebele 9/ at the south of Kidame Gebeya(market place). The place which is mostly attributed as slum is sometimes named as (Gojjo Sefere or plastic housing) and has 83 households with average number of 4 family members. The researcher has observed that the area is the most congested and overcrowded and densely concentrated at the southern edge of the market place. As it is at the edge of the market place, the area is served as garbage of the wastes from the market.

The accessibility of different social services such as water services, public toilet, health centers etc are very difficult. During field observation, the researcher has noticed that the area is exposed for open defection. Moreover, there is no garbage box around and absence of commonplace for disposal of waste. Generally, the area is characterized by poor waste management system and serious sanitation problem that affect the health of the dwellers. Here below the picture shows what the study area Gojjo Sefer (plastic housing ) looks like. 


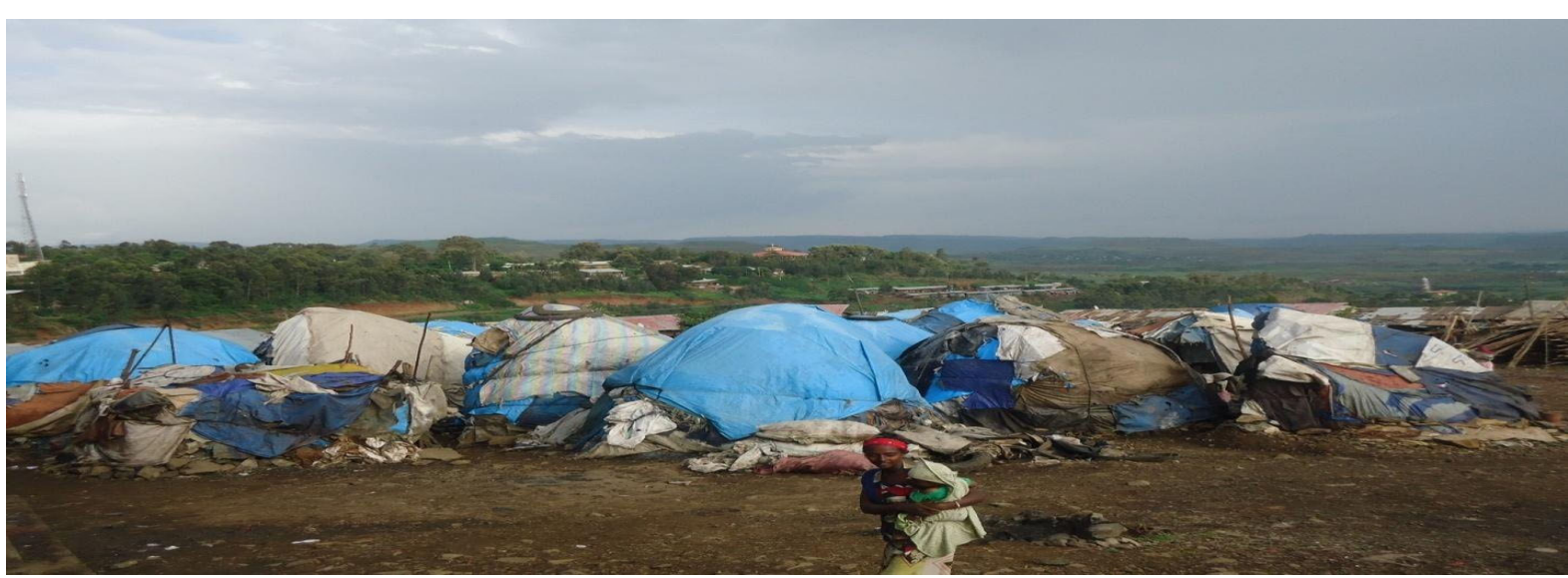

Figure 1: Sample photo of Goijo Sefer

Source: Photo taken during fieldwork

\section{Livelihood of the dwellers}

According to finding obtained from interviewees, the livelihood of people in the area is depending on small and informal business. Men are involved in daily labors and very few in traditional handcraft like blacksmith, weaver, tailor and carpenter. Most of them are engaged in faire wood marketing--buying and reselling wood by cutting it into different sizes.

As to the response from the research participants, most women are engaged in petty trading such as Gulit Gebeya street vending and paid domestic works. Respondents explained that some are even engaged in commercial sex works. Those who are elderly, sick and who with HIV/AIDS have been engaged in bagging around the market and church. This makes their living worse and miserable for the small source of income is not enough to feed their family, and pay for health services. This in turn led them to engage in bagging.

A 57 years old dweller of the study area was explaining the economic situation as follows

I have been living here since 1989. I come from rural area, because of lack of enough income to support my family. My family themselves come to Gondar and this place following my coming to the place. I am now getting old and tired. But still I have been striving to support my family by buying fire wood and reselling it for little profit. Sometimes Nongovernmental organizations Especially Yenege Tesfa Orphan and Street Children Organization and provide us with plastic for our house, food - cereal and blanket during summer season. University of Gondar provided us with meat during annual festivities like Easter. As these aids are mostly occasional, we are not able to lead our life in a way that is different from the previous.

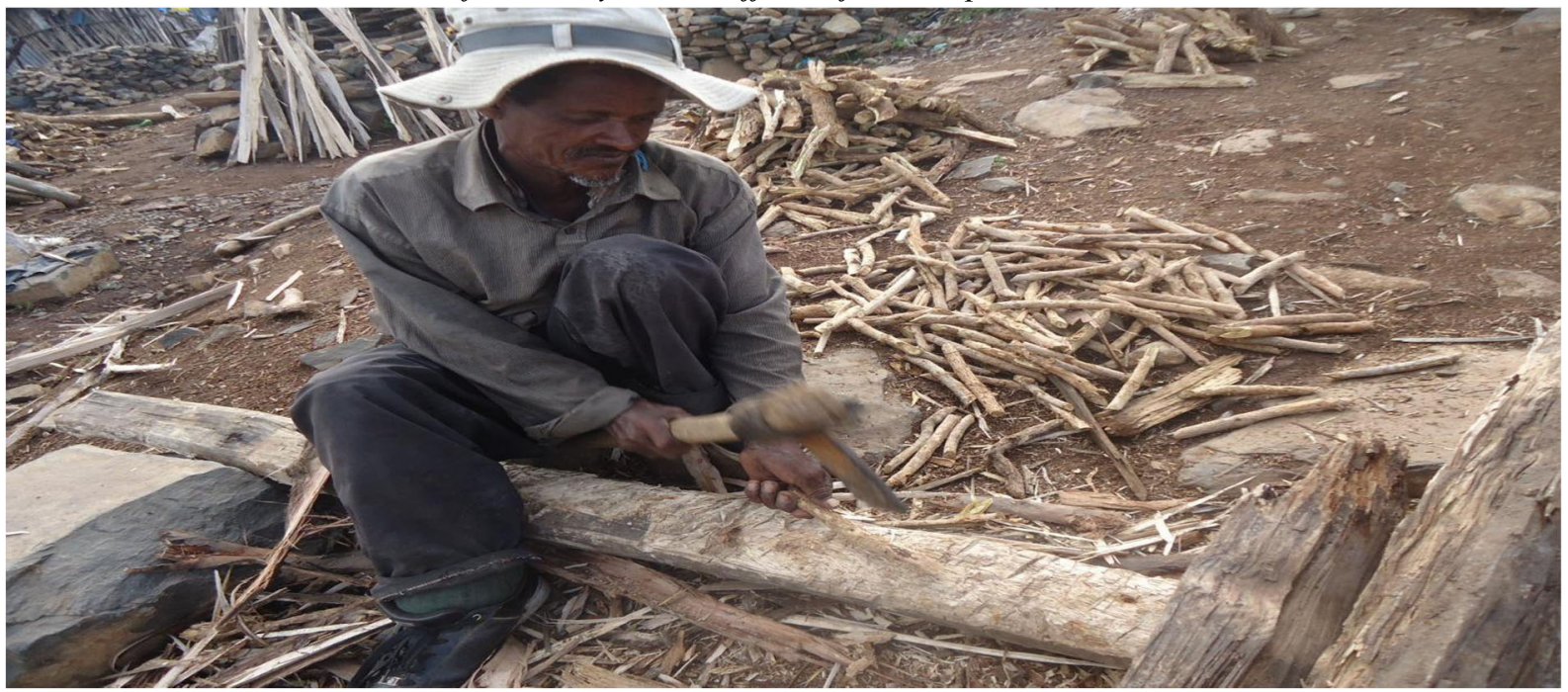

Figure 2: A man in the study area preparing wood for sell.

Source: Photo taken during fieldwork

The health status of the dwellers

As to researcher's filed observation, in Gojjo sefer, there is no adequate waste management system in the area. The households had no enough toilet facility and sanitations. 
Similarly, the finding from key informant interview revealed that dwellers of Gojjo sefer have unhygienic latrines. As a result, they had to face any illness at least in two to three months and most frequent illness that they face is diarrhea and at seconds the fever. Among the family members, most victims of illness are children who are more vulnerable to pathogens of different diseases. Chronic diseases (like HIV/AIDS and hepatitis) are also common for women and elders. The expert explained that, since the dwellers could not afford to get health service, Yenege Tesfa Orphan and Street Children Organization is working to support them- cover small health service costs. YTOSCO has also been trying to provide tanning about sanitation, personal hygiene, HIV/AIDS and family planning through coffee ceremony

Supporting this, participants mentioned that, since they have been oriented by experts, from Yenege Tesfa Orphan and Street Children Organization (YTOSCO), their household members practice washing hands. However, they stated that, unfortunately most of the dwellers do not wash their hands with soap as mostly they lack it. The dwellers of this slum do not have adequate system of latrine cleanliness. Consequently, they have been facing different health problems such as diarrhea and at seconds the fever. Dwellers of this slum area have no adequate access to health except mini support by charity organization

\section{Social Network of the dwellers of the area under study}

The finding from the interview indicates that overall social conditions of the dwellers of Gojjo Sefer are very cohesive and strong. Since the number of dwellers is small and they are living in a very close neighboring, they know one another. They gather frequently in different groupings for coffee ceremonies festivals and other occasional events. By this, they share their sorrow and success, help each other during social crisis.

According to the Sub City Official, social bond among these slum dwellers is different from the social bond of the theoretical slum dwellers. They have high social network and attributed by collectivity. The sub city administration has restricted the entry of new immigrants to the existing members in the area. This enables the old dwellers in the area to feel as a unique community and they cooperate one another. Even though, member of the family are engaged in different activities to generate income, cultural value systems such as helping one another and respecting elders are still significant in the area.

A woman from participants explained the social network as follows:

I am 35 years old. I lived here for 13 years. I am HIV positive. I have 5 children and my husband is died. Because of this, I cannot work and support my family properly. However, the people in my neighbor help me by providing advice and sometime food while I am sick. Most of us lived here for long period; we get together when we are given trainings and other meetings, therefore we know each other; we also gather during funerals if there is death in the community. In this way, we cooperate to support one another.

\section{Discussion}

As noticed from field work and readings, slums could be resulted from rural urban migration and internal displacement. This happened in the historic city Gondar. As to the key informant-Arada sub city officer, most the dwellers in the slum area under study are immigrants from different area around Gondar. Similarly, finding from the respondents indicates that Gojjo sefer slum area residents come to Gondar because of certain push factors such as unfair distribution of farmland, infrastructural problems, unemployment in rural areas and family disorganization. They migrated to the city and settle at this place. Most of them are women and those who are sick and could not able to support their family properly. As a result, since they could not afford living cost, they settle at Gojjo sefer slum area. The area is characterized by the houses typically constructed by stone and plastic. Since the area is not planed, marked by low road facilities, crude movement, poor sanitation and congestion.

Means of livelihood in Gojjo sefer are daily labor, traditional handcraft, and domestic work and for some women commercial sex work and some of these are engaged in bagging. These livelihood strategies enable them not to change but simply to survive their lives. Because of deteriorated housing, poor sanitation and hygiene of the area, dwellers of Gojjo sefer are suffering from different health problems such as diarrhea, fever and other water born diseases.

Though they are having these and other adversities, slum dwellers at Gojjo sefer have been copping the life challenges with strong social bonds and collectivities among the neighbors. as the respondents explained, since most of them lived together, shared same socio economic statuses, same psycho social traits for long period of time, they have established very cohesive social networks and therefore help one another during social, economic and health crisis.

\section{Conclusion}

The study area was at Gondar City, Arada sub city /Kifle ketema slum area called Gojjo sefer. The area is characterized by congested and poorly constructed housing, inadequate infrastructure and social service provision, place of petty commercial activities. Most of the dwellers are immigrants from rural area and the household size 
is larger than usual. On the average more than 4 people had to live in one room. Livelihood strategies of the dwellers could not enable them securing the necessities of life. Monthly income is too low to provide good facilities to large households. Because of these, people in the slum area of the city have being suffered from a variety of interrelated problems. Some problems include poor infrastructure, poor sewage disposal system, low water provision, personal hygiene and lack of health care services. Accordingly, dwellers are exposed to frequent disease such as diarrhea, fever and chronic illnesses. Since the dwellers in the slum are living for long collectively, they have shared values, culture and norms. These help them to established strong social network among themselves and use it as copping mechanism of slum adversities.

\section{The way forward}

As the finding from key informants, previously the City municipality tried to settle these slum dwellers by building houses with certain class made up of iron sheets wall and roof. This place is far from the area where dwellers had been living. The local government merely moved them from sulm-Gojjo sefer and settled at the new site where there is no transport access, no market or access to means of livelihood for elderly and the sick. This destructed social and economic integration of dwellers with their place. As a result, they returned and settled at their previous place Gojjo sefe. They preferred living in plastic housing and secure the old means of livelihood and social integration. Standing from this and other findings, the researcher put some recommendations. First of most, collaborative organization should be committed and able to fulfill the primary needs of the poor urban dwellers of the city. They should also educate dwellers how to improve their livelihood, health and how to keep clean their environment as far as they have to live collectively at same place. Moreover, as everlasting solution, the local government with NGOs should formulate and implement projects like slum upgrading in the area without destructing the social, cultural and economic integration of the dwellers. Finally, the government should control rural urban migration implementing rural employments strategies, create job opportunities for the old migrants

\section{References}

Alamgir et al. (2009). "Assessing the livelihood of slum ewellers in Dhaka city." J.Bangladesh Agril. Univ., 7(2), $373-380$.

Berger, T, (2006). Slum Areas and Insecure Tenure in Urban Sub-Saharan Africa - A Conceptual Review of African Best Practices. UPPSALA UNIVERSITET, Stochhom.

Hermela, A. (2018). Resilient factors and Adversities of kosheseffer survivors: Green social work perspective, Unpublished MSW thesis, Addis Ababa University.

Nayak. K.B, (2013) , The Plight of Slum Dwellers at Gondar City in Ethiopia. International Journal of Management and Social Sciences Research,Volume 2, No. 10.

UN - HABITAT (2003) The challenge of slums global report of human resettlement earth scah, London

World Bank. (1993) population expansion, VOl, 20, oxford universitypress.

World Bank (2011), “The Millennium Development Goals Report”, World Bank 